\title{
FORMULATION OF TETRANDRINE BEADS USING IONIC GELATION METHOD CA-PECTINATE COATED PH-SENSITIVE POLYMERS AS COLON-TARGETED DOSAGE FORM
}

\author{
RADITYA ISWANDANA ${ }^{1 *}$, KURNIA SARI SETIO PUTRI ${ }^{1}$, CINDY ESPREANCELLY SANDIATA ${ }^{1}$, SISILIA TRIANI ${ }^{1}$, \\ SANTI PURNA SARI ${ }^{2}$, JOSHITA DJAJADISASTRA ${ }^{1}$
}

${ }^{1}$ Laboratory of Pharmaceutics and Pharmaceutical Technology Development, Faculty of Pharmacy, Universitas Indonesia, Depok 16424, Indonesia. ${ }^{2}$ Laboratory of Pharmacology and Toxicology, Faculty of Pharmacy, Universitas Indonesia, Depok 16424, Indonesia.

Received: 15 May 2017, Revised and Accepted: 14 June 2017

ABSTRACT

Objectives: Pectin, a natural polysaccharide, can be used as colon targeted drug delivery systems. Ionotropic gelation of pectin in the presence of certain divalent cations, such as calcium ions, protects drugs by producing insoluble hydrogels that can be used as a colon-targeted drug delivery carrier. In this study, calcium pectinate beads containing tetrandrine were made and were evaluated for in-vitro drug release and in-vivo study.

Methods: Calcium pectinate beads were prepared by ionic gelation method with varied calcium chloride concentration ( $5 \%$, $10 \%$, and $15 \%$ ). The best formula was coated with pH sensitive polymers, i.e., Eudragit L100-55, Eudragit L100, hydroxypropyl methylcellulose phthalate HP-55 or cellulose acetate phthalate.

Results: Characterization results showed that the beads produced were quite spherical and had yellow-brownish color. After the coating process, beads were used in in-vitro drug release and targeted test. From in-vitro release study, beads coated with Eudragit L100 $10 \%$ has shown good colon targeted dosage form with percent cumulative release $57.87 \%$. This result also confirmed with the in-vivo test. Beads which were coated by Eudragit L100 10\% could be found in the rat intestine.

Conclusion: Formula 1 (5\% calcium chloride concentration) was chosen as the best beads characterization. Formula $1 \mathrm{C}$ ( $5 \%$ beads coated with $10 \%$ Eudragit L100) showed an optimal protection from gastric acid in the in-vitro release study and able to deliver the beads to the intestine in the in-vivo targeted test.

Keywords: Beads, Tetrandrine, Calcium pectinate, Ionic gelation, Colon-targeted.

(C) 2017 The Authors. Published by Innovare Academic Sciences Pvt Ltd. This is an open access article under the CC BY license (http://creativecommons. org/licenses/by/4. 0/) DOI: http://dx.doi.org/10.22159/ajpcr.2017.v10i10.19994

\section{INTRODUCTION}

Natural polymer, such as pectin, provides a potential in pharmaceutical industry application. Pectin has several unique properties that have enabled it to be used as a matrix for the entrapment and/or delivery of a variety of drugs, proteins, and cells. Pectin had been widely used as a carrier to deliver drugs to the digestive tract, including tablet matrix, gel beads, and film-coated dosage form. Pectin can be used as colon-targeted drug preparations because it has a long retention in the gastrointestinal tract and a complete degradation by the living bacteria in the intestine. Besides that, pectin is nontoxic, biodegradable, and biocompatible [1].

Drugs delivery system to the colon should provide protection of the drugs during the delivery to the colon, which including prevent the release and drug absorption in the stomach and intestine, then the bioactive release and absorption can happen in the colon [2]. Drugs delivery system to the colon has certain challenges because the colon is the furthest segment in the gastrointestinal tract and a colon-targeted formulation will be affected by various condition and environment during the delivery via the gastrointestinal tract, including the $\mathrm{pH}$, enzyme, electrolyte, transit time, and pressure [3].

Drug formulation with $\mathrm{pH}$ sensitive polymer can protect the active substance from gastric acid and proximal of the small intestine. This $\mathrm{pH}$-sensitive polymer can tolerate dissolution in the gastric acid environment; however, it can be dissolved in a higher $\mathrm{pH}$ in the intestine. This $\mathrm{pH}$-sensitive polymer can be split in ileum terminal $\mathrm{pH}$, thus providing a targeted drug delivery to the colon [4]. Several examples of $\mathrm{pH}$-sensitive polymer which commonly used for colon targeted drug delivery were methacrylate polymer in acid-base, known as Eudragit.
Eudragit L100-55 and Eudragit L100 was used as pH sensitive coat to inhibit drug release in the gastric and targeting the release in the intestine [5]. Furthermore, hydroxypropyl methyl cellulosephthalate (HPMCP) HP-55 and cellulose acetate phthalate (CAP) can be used for this purpose.

At present, there are several antifibrotic compounds under research, such as galunisertib [6], rosmarinic acid [7], and tetrandrine. We used tetrandrine as an antifibrotic drug model. Tetrandrine was an alkaloid isolated from Stephania tetrandra S. Moore root, studied as an inhibitor working in transforming growth factor (TGF- $\beta$ ) signaling pathway (TGFinhibitor) [8]. Therefore, it was expected to have potential in intestinal fibrosis treatment. Intestinal fibrosis was a common complication of inflammatory bowel disease and can happen in ulcerative colitis and Crohn's disease (CD), but more often appear on CD. Fibrosis as the consequences of local chronic inflammation was indicated with an abnormal deposition in matrix extracellular which led to organ dysfunction [9].

In this study, we developed a colon-targeted preparation, such as tetrandrine beads, using ionotropic gelation method, with pectin as the polymer and $\mathrm{Ca}^{2+}$ as the crosslinker, and coating the beads using pH sensitive polymer, i.e., Eudragit L100-55, Eudragit L100, HPMCP HP-55, or CAP. The final beads then characterized and conducted a test to obtain the drug release profile.

\section{MATERIALS AND METHODS}

Materials

Tetrandrine (Shaanxi Ciyuan Biotech, China), pectin (Danisco, United States of America), calcium chloride (Merck, Germany), Eudragit L100- 
55 (Evonik, Germany; obtained from PT. Jebsen \& Jessen Technology, Indonesia), Eudragit L100 (Evonik, Germany; obtained from PT. Jebsen \& Jessen Technology, Indonesia), CAP (Eastman, USA; obtain from Eastman Chemical Company, Singapore), hydroxypropyl methyl cellulose phthalate HP-55 (Shin Etsu, Japan; obtained from PT Lawsim Zecha, Indonesia), talc (Brataco, Indonesia), triethyl citrate (Weifang Limin Chemical, China; obtained from PT. Lawsim Zecha, Indonesia), chloride acid (Merck, Germany), potassium phosphate monobasic (Merck, Germany), sodium hydroxide (Merck, Germany), acetone (Brataco, Indonesia), isopropanol (Brataco, Indonesia), and deionized water (Brataco, Indonesia).

\section{Animals}

The Sprague-Dawley male rats with a weight of 260-330 g from Badan Penelitian dan Pengembangan Kesehatan (Balitbangkes, Indonesia).

\section{Calcium pectinate beads preparation}

Pectin in $5 \%$ concentration was dissolved in distilled water. Then, tetrandrine was dissolved in $\mathrm{HCl} 0.5 \mathrm{~N}$. Pectin and tetrandrine solutions mixed and stirred until homogeneous. Then, the pectin solution which already contained tetrandrine was shed using syringe needle in $26 \mathrm{G}$ size to the medium containing calcium chloride in $200 \mathrm{rpm}$ stirring rate. Beads produced in calcium chloride were stored for 15 minutes. Then, the beads were separated from the solutions and rinsed with deionized water three times and dried at room temperature. All beads formulae can be seen in Table 1 .

\section{Beads coating process with $\mathrm{pH}$-sensitive polymers}

Eudragit L100-55 was mixed with plasticizer, and talc thus can be obtained a $10 \%$ and $12.5 \%$ Eudragit L100-55. The plasticizer used was triethyl citrate in 25\% concentration of Eudragit L100-55 mass used [10]. All coating materials then dissolved in acetone:isopropanol (1:1). Beads which would be coated were added to Eudragit L100-55 solutions while stirred. In beads coating with Eudragit L100, the coating was performed with a similar method and condition with Eudragit L100-55 for beads coating.

For CAP, a $10 \%(\mathrm{w} / \mathrm{v})$ and $15 \%(\mathrm{w} / \mathrm{v})$ solution in acetone were used for coating and triethyl citrate $(25 \%, w / w)$ was used as a plasticizer. In the case of coating with HPMCP, a $10 \%(\mathrm{w} / \mathrm{v})$ and $12 \%(\mathrm{w} / \mathrm{v})$ solution in acetone were used and triethyl citrate $(2 \mathrm{ew} 5 \%, \mathrm{w} / \mathrm{w})$ was used as a plasticizer. Coating formula can be seen in Table 2 .

\section{Beads characterizations}

Shape

Beads surface shape were observed using an optical microscope.

Table 1: Calcium pectinate beads formulations

\begin{tabular}{llll}
\hline Formula & Pectin $(\%, w / v)$ & $\begin{array}{l}\text { Calcium } \\
\text { chloride } \\
\text { (\%, w/v) }\end{array}$ & Pectin:Tetrandrine \\
\hline 1 & 5 & 5 & $1: 1$ \\
2 & 5 & 10 & $1: 1$ \\
3 & 5 & 15 & $1: 1$ \\
\hline
\end{tabular}

\section{Morphology}

Beads were coated with gold metal and put in the sample holder. The sample then observed under vacuum with scanning electron microscope (SEM; LEO 420i, United Kingdom).

\section{Particle size distribution}

The diameters of 300 beads were measured using an optical microscope.

\section{Water content}

Moisture content was determined using moisture balance (AMB 50, United Kingdom). $1 \mathrm{~g}$ of the beads was weighed. The samples were then placed on the aluminum pan and dried completely at an elevated temperature until no further weight change was observed.

\section{Thermal test}

The test was performed using differential scanning calorimetry (PerkinElmer STA 6000, USA) on tetrandrine, pectin, $\mathrm{CaCl}_{2}$, calcium pectinate beads, also calcium pectinate beads containing tetrandrine. A total of $5.0 \mathrm{mg}$ sample was put into a crucible $10.0 \mu \mathrm{l}$, then heated and measured from 25 to $300^{\circ} \mathrm{C}$ with the heating rate was $10^{\circ} \mathrm{C} /$ minutes. Nitrogen gas was used as purge gas with a $100 \mathrm{ml} /$ minutes flow rate.

\section{$X$-ray diffraction}

X-ray diffraction test (Philips PW 2213/20, The Netherlands) was performed on tetrandrine and calcium pectinate beads containing tetrandrine. The X-ray diffraction pattern was recorded using diffractometer $\mathrm{X}$-ray radiation with $\mathrm{Cu}$ as the anode and graphite monochromatic, operate in $40 \mathrm{kV}, 30 \mathrm{~mA}$.

\section{Process efficiency}

Process efficiency was defined by comparing total dry beads weight obtained against total material used during the beads production. The recovery value could be obtained with this following formula:

$$
\text { Process efficiency }(\%)=\frac{\mathrm{Wm}}{\mathrm{Wt}} \times 100 \%
$$

$\mathrm{Wm}=$ Beads weight obtained $(\mathrm{g})$

$\mathrm{Wt}=$ Total beads material weight $(\mathrm{g})$.

\section{Entrapment efficiency}

Tetrandrine content test in the beads was performed by weighing carefully $\pm 50.0 \mathrm{mg}$ beads, then soaked in $10.0 \mathrm{ml}$ phosphate buffer pH 6.8 for 24 hrs. After 24 hrs, the solutions were stirred with a magnetic stirrer at $100 \mathrm{rpm}$ and heated in $37^{\circ} \mathrm{C}$ until they disintegrated. The disintegrated beads then mixed in phosphate buffer $\mathrm{pH} 6.8$ with $\mathrm{HCl}$ $0.1 \mathrm{~N}$ addition until obtained $50.0 \mathrm{ml}$ volume, then put into centrifuge tubes and separated from centrifugation device for 10 minutes at $2500 \mathrm{rpm}$. After separated, the supernatant was collected then adding $\mathrm{HCl} 0.1 \mathrm{~N}$ until obtaining $100.0 \mathrm{ml} .20 \mathrm{ml}$ solution was pipetted, put in $50.0 \mathrm{ml}$ volumetric flask and adding phosphate buffer $\mathrm{pH} 6.8$ until reaching the absorption limit. Tetrandrine absorption was measured using spectrophotometer ultraviolet (UV)-visible (Shimadzu UV-1800,

Table 2: Beads coating formulations

\begin{tabular}{llllll}
\hline Formula & Polymer & Concentrations $(\%, \mathbf{w} / \mathbf{v})$ & Plasticizer concentrations $(\%, \mathbf{w} / \mathbf{w})$ & Talc $(\%)$ & Solvent \\
\hline A & Eudragit L100-55 & 10 & 2.5 & 5 & \\
B & Eudragit L100-55 & 12.5 & 3.125 & 6.25 & Acetone:Isopropanol \\
C & Eudragit L100 & 10 & 2.5 & 5 & $(1: 1)$ \\
D & Eudragit L100 & 12.5 & 3.125 & 6.25 & \\
E & HPMCP HP-55 & 10 & 25 & 5 & Acetone \\
F & HPMCP HP-55 & 12 & 25 & 6 & \\
G & CAP & 10 & 25 & 5 & \\
H & CAP & 15 & 25 & 7.5 & \\
\hline
\end{tabular}


Japan) at $280 \mathrm{~nm}$ wavelength. Tetrandrine content was measured by comparing the calibration curve thus the tetrandrine entrapped could be measured.

Entrapment percentage (\%) obtained by comparing the core total content obtained with the total core theoretic, was measured using the following formula:

$$
\text { Entrapment efficiency }(\%)=\frac{\text { Total } \text { core measured }}{\text { Total } \text { core theoretic }} \times 100 \%
$$

\section{Swelling test}

$2.5 \mathrm{~g}$ beads sample from each formula was weighed $\left(\mathrm{W}_{1}\right)$ then placed on weighing dishes. $25 \mathrm{ml}$ phosphate buffer $\mathrm{pH} 6.8$ was added and stayed aside to expand in the room temperature. After 5 minutes, the sample was collected from the container, carefully dried and the rest of the medium was absorbed by filter paper, then weighed $\left(\mathrm{W}_{2}\right)$. After the sample had been weighed, they were put back into the medium. The weighing was following the same procedure which was performed in 5 , $10,15,30,60,90,120$, and 180 minutes. Swelling ability was measured using the following formula:

$$
\text { Swelling ability }(\%)=\frac{w_{2}-w_{1}}{w_{1}} \times 100 \%
$$

$\mathrm{W}_{1}=$ Dry sample weight

$\mathrm{W}_{2}=$ Hydrated sample weight.

\section{In-vitro release study}

The in-vitro release study was performed in hydrochloride acid $0.1 \mathrm{~N}$ $\mathrm{pH} 1.2$, phosphate buffer $\mathrm{pH} 7.4$, and phosphate buffer $\mathrm{pH} 6.8$ media. Media volume used was $200.0 \mathrm{ml}$ in $37 \pm 0.5^{\circ} \mathrm{C}$ using magnetic stirrer in $100 \mathrm{rpm}$ rate. The drug release time in chloride acid $0.1 \mathrm{~N} \mathrm{pH} 1.2$ medium was observed for $2 \mathrm{hr}$, in phosphate buffer $\mathrm{pH} 7.4$ medium was observed in $3 \mathrm{hrs}$, and the phosphate buffer $\mathrm{pH} 6.8$ medium was observed in $3 \mathrm{hrs}$. $100 \mathrm{ml}$ beads were weighed and put in the filter bag then put into the dissolution medium. $10 \mathrm{ml}$ sample was collected, then the collected sample solution was immediately replaced with the same medium in some certain times. The absorption of the sample then measured using spectrophotometer UV-visible.

Measurement of the substance contained in the sample at n-minute was measured using the following formula:

$$
\text { n minute }=\frac{(y n-a) x f p x M}{b \times 1000}+\ldots+\frac{(y 15-a) x f p x S}{b \times 1000}
$$

$$
\begin{aligned}
& \mathrm{y}=\text { tetrandrine absorption } \\
& \text { yn = tetrandrine absorption in } n \text { minute } \\
& \mathrm{x}=\text { tetrandrine concentration } \\
& \mathrm{fp}=\text { dissolution factor } \\
& \mathrm{M}=\text { volume of release medium } \\
& \mathrm{S}=\text { sampling volume } \\
& \mathrm{a}=\text { intercept coefficient } \\
& \mathrm{b}=\text { slope. }
\end{aligned}
$$

\section{In-vivo targeted test}

The in-vivo targeted test was performed qualitatively to define the beads toleration against gastric and proximal intestine $\mathrm{pH}$ thus could reach the colon. The test was performed in the Sprague-Dawley male rats with a weight of 260-330 g. Before performing the test, we conducted time orientation of the dissection. Beads were mixed in $\pm 5.0 \mathrm{ml}$ water and injected into the rats using gastric injection with the dissection times were 1, 1.5, 2, 2.5, and 3 hrs [11]. The beads tested on rats were beads with coating formula which provided the best in-vitro release profile. Rats were separated into two groups, which were: (1)
Beads without coating as control and (2) beads with the best coating. The rats were dissected in the time determined before according to the orientation result, and the colon condition was observed. Drugs targeted test was said successful if the beads found attached to the intestine. The experiments were approved by the Ethical Committee of Cipto Mangunkusumo Hospital, Faculty of Medicine, Universitas Indonesia with ethical approval Reg. No. 319/UN2.F1/ETIK/2016.

\section{RESULTS AND DISCUSSION}

\section{Calcium pectinate beads}

Production was performed with $5 \%$ pectin solution and the concentration of calcium chloride (5\%,10\%, and $15 \%$ ) with tetrandrine and pectin ratio used was 1:1. Pectin in 5\% concentration was dissolved in deionized water. Then, tetrandrine was dissolved in $\mathrm{HCl} 0.5 \mathrm{~N}$. Pectin and tetrandrine solutions were mixed and stirred until homogeneous using stirrer. Then, the pectin solutions that had contained tetrandrine were shed using syringe needle in $26 \mathrm{G}$ size into medium containing calcium chloride on $200 \mathrm{rpm}$ stirring rate. When the pectin and tetrandrine mixtures were shed on calcium chloride, beads would immediately have shaped by ionotropic gelation process. This process was happened because of the cross-linked between pectin carboxylate groups which had negative load and calcium with the positive ion. Beads obtained in calcium chloride solution was stored for 15 minutes. Then, the beads were separated from the solutions and rinsed with distilled water three times and dried. The drying process then performed in $25^{\circ} \mathrm{C}$ room temperature for around 2 days.

\section{Beads coated with pH-sensitive polymer}

Calcium pectinate beads coating was performed to hold tetrandrine release in the upper part of gastrointestinal tract. This experiment was used Eudragit L100-55, Eudragit L100, HPMCP HP-55, or CAP. Calcium pectinate beads containing dry tetrandrine were put into coating solution which had been thickened. After a continuous stirring, beads were separated from the coating solution, dried with a warm air, then separated one by one.

\section{Beads characterizations \\ Beads shape}

According to the observation, the wet beads were found spherical in a yellowish clear color. After dried on filter paper at room temperature, the beads became brownish yellow, the size was changed and the beads visually still showed spherically. According to the visual observation, Formula 1 had the smallest beads size and the driest textures. Formula 2 had a bigger size than Formula 1 and the beads were found more moisture. Formula 2 beads had a paler color compared with Formula 1 and felt a bit sticky. In Formula 2, beads found in the biggest size, a pale yellow, and had a characteristic like Formula 2 which were found sticky. Formula 1 was determined as the best formula with the best shape and morphology. These results can be seen in Fig. 1.

\section{Morphology}

According to the SEM results under 1000x magnification (Fig. 2), on Formula 2 and Formula 3 showed that calcium chloride concentrations affected the beads surface characterization, where the higher the calcium chloride concentrations then the beads obtained would be softer and got fewer pores. These results showed that the beads would be more rigid.

\section{Particle size distribution}

Beads particle size distribution was evaluated using the optical microscope in $10 \times$ magnification for Formula 1 and $4 \times$ magnification for Formula 2 and 3. Formula 1 which was distributed in 741-810 $\mu \mathrm{m}$ was found in 29\%, Formula 2 which was distributed in 1179-1256 $\mu \mathrm{m}$ was found in $37 \%$, and Formula 3 which was distributed in 1179$1256 \mu \mathrm{m}$ was found in $46.67 \%$.

Coated particle beads size distribution evaluation also performed using an optical microscope with $4 \times$ magnification. Formula $1 \mathrm{~A}$ which was 


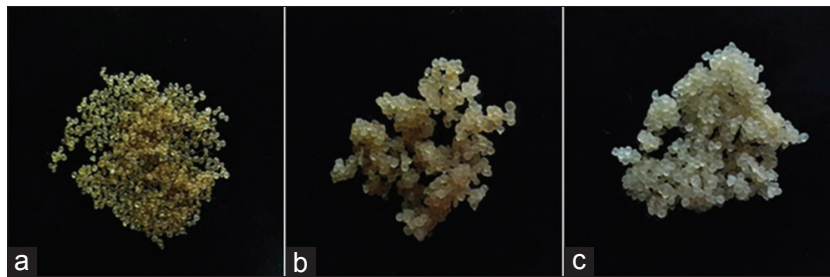

Fig. 1: The appearance of dry beads with varying concentrations of calcium chloride, (a) Formula 1, (b) Formula 2, (c) Formula 3
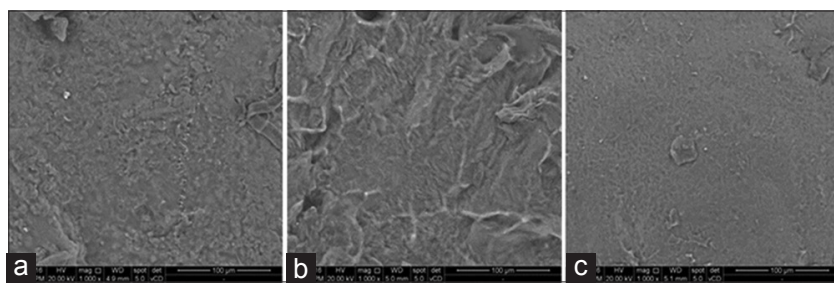

Fig. 2: SEM observation results under $1000 \times$ magnification, (a) Formula 1, (b) Formula 2, (c) Formula 3

distributed in particle size $975-1065 \mu \mathrm{m}$ was found in 34\%, Formula $1 \mathrm{~B}$ which was distributed in particle size 976-1040 $\mu \mathrm{m}$ was found in $59.33 \%$, Formula $1 \mathrm{C}$ which was distributed in particle size $975-1079 \mu \mathrm{m}$ was found in $56.67 \%$, Formula 1D which was distributed in particle size 975-1040 $\mu \mathrm{m}$ was found in $58.67 \%$, Formula 1E which was distributed in particle size $1080-1119 \mu \mathrm{m}$ was found in $29.33 \%$, Formula $1 \mathrm{~F}$ which was distributed in particle size 1075-1174 $\mu$ m was found in 55.33\%, Formula $1 \mathrm{G}$ which was distributed in particle size 1000-1029 $\mu \mathrm{m}$ was found in $22.67 \%$, and Formula $1 \mathrm{H}$ which was distributed in particle size $1105-1139 \mu \mathrm{m}$ was found in $30.00 \%$.

Based on the particle distribution results, the beads produced did not have a uniform particle size distribution. This could be caused by the pressure difference in the shedding process of pectin and tetrandrine mixtures to the calcium chloride solutions. The average beads diameter showed that the bigger size was obtained while using a higher concentration of calcium chloride used. This proved that the big beads size could be affected by calcium chloride concentration. The excess calcium ion may cause all part experience cross-link thus it would create a bigger bead; therefore, the higher the calcium chloride used then the bigger the beads size obtained $[12,13]$.

\section{Water content}

Results of beads water content from the three formulae showed that the water contained was found between 28.75 and $40.51 \%$. Efficiency process results toward the dry beads obtained from Formula 1, 2, and 3 were $28.75 \pm 11.3 \%, 29.63 \pm 1.01 \%$, and $40.51 \pm 0.88 \%$, respectively. The water content also measured on the coated beads. Results of the coated beads from four formulae showed that the total water contained was found between $8.67-13.74 \%$. Efficiency process results on the dry beads obtained from Formula 1A-D were $10.36 \pm 0.66 \%, 12.65 \pm 0.53 \%$, $12.65 \pm 0.53 \%$, and $8.67 \pm 0.62 \%$, respectively.

Water content results showed that each beads formula contain a high concentration of water. The high-water content could be caused by the high concentrations of calcium chloride in crosslink solutions which were $5-15 \%$. Calcium chloride had a hygroscopic property so that it affected the water content of the beads. Moreover, the coated beads had lower water content. This low water content could be caused by the acetone usage as the solvent of the coating materials; thus, they experienced evaporation.

\section{Process efficiency}

Process efficiency was calculated by comparing the total weight of the obtained dry beads to the total of raw materials used during preparation.
Beads materials used were pectin, tetrandrine, and calcium chloride. The process efficiency process results of dry beads from Formula 1, 2, and 3 were $34.44 \%, 21 \%$, and $31.25 \%$, respectively.

The process efficiency showed the not too high results could be caused by the beads were experiencing size shrinkage after drying process; thus, they lost moisture in the polymer which causing a lower dry beads weight.

\section{Entrapment efficiency}

Entrapment efficiency determination was calculated based on the concentration of tetrandrine in the beads. Entrapment efficiency was performed by soaking the beads in phosphate buffer medium $\mathrm{pH} 6.8$ so that the beads would expand and release the drugs. Then, adding $\mathrm{HCl}$ to dissolve the tetrandrine. Entrapment efficiency obtained for Formulas 1-3 were $65.67 \%, 68.03 \%$, and $56.28 \%$, respectively.

\section{Thermal test}

The thermal test was performed on tetrandrine, pectin, $\mathrm{CaCl}_{2}$, calcium pectinate beads, also calcium pectinate containing tetrandrine. The test was performed using differential scanning calorimeter device. Results of tetrandrine thermogram showed an endothermic peak at $219.32^{\circ} \mathrm{C}$. Calcium chloride had an endothermic peak at $161.64^{\circ} \mathrm{C}$. Pectin had two endothermic peaks which were at $75.70^{\circ} \mathrm{C}$ and $153.11^{\circ} \mathrm{C}$. Empty calcium pectinate beads had two endothermic peaks which were at $88.33^{\circ} \mathrm{C}$ and $174.56^{\circ} \mathrm{C}$. Calcium pectinate beads containing tetrandrine showed an endothermic peak at $179.48^{\circ} \mathrm{C}$. These results are illustrated in Fig. 3.

\section{$X$-ray diffraction}

X-ray diffraction test was performed to detect the drug polymorphism after gelation process [14]. The pattern of tetrandrine showed a dominant crystalline phase; this showed by sharp and tall diffractions. The decreased tetrandrine peak intensity can be found in calcium pectinate beads containing tetrandrine; this showed that there was physical interaction. Tetrandrine was transformed from a crystalline phase to amorphous phase in calcium pectinate beads. These results can be seen in Fig. 4.

\section{Swelling test}

Beads ability to swell was observed in phosphate buffer medium $\mathrm{pH} 6.8$ for $3 \mathrm{hrs}$ at room temperature. In phosphate buffer medium $\mathrm{pH} 6.8$ testing, they showed that Formula 1 expanded by $186.35 \%$, Formula 2 expanded by $156.77 \%$, and Formula 3 expanded by $151.17 \%$.

Phosphate buffer pH 6.8 was used as a medium to simulate a colon fluid $\mathrm{pH}$. The aim of swelling ability test was to define the ability of beads to swell when beads had reached the colon. Based on the swelling test result, the increase in calcium chloride concentration reduced the pectin's ability to swell. By increasing the calcium chloride concentration, reduced the total water that passed through the beads produced particles with denser structures and reducing beads permeability, thus the higher concentration of calcium chloride used then the beads ability to swell was reduced [15].

\section{In-vitro release test}

In hydrochloride acid pH 1.2 medium, beads with $10 \%$ and $12.5 \%$ Eudragit L100-55 formulas showed the cumulative drug release were $21.88 \%$ and $10.51 \%$. Eudragit L100-55 in $12.5 \%$ concentration could maintain a better drug release. However, beads with Eudragit L100 could maintain a better drug release than Eudragit L100-55. The cumulative drug release in $\mathrm{HCl}$ medium for Formula $1 \mathrm{C}$ was $3.54 \%$ and $1 \mathrm{D}$ was $6.33 \%$. While beads coated with phthalate polymer could not resist tetrandrine released better than the methacrylate polymer in acidic medium.

In phosphate buffer $\mathrm{pH} 7.4$, it was expected that the coat still could hold drug release. Absorption showed that the value was starting to increase. 
This showed that the drugs slowly had been released from the beads. The cumulative drug release in phosphate buffer $\mathrm{pH} 7.4$ for Formula $1 \mathrm{~A}$ was found in $37.90 \%$ and for Formula $1 \mathrm{~B}$ was found in $27.97 \%$. Beads with Eudragit L100 coat had a lower drug release compared with

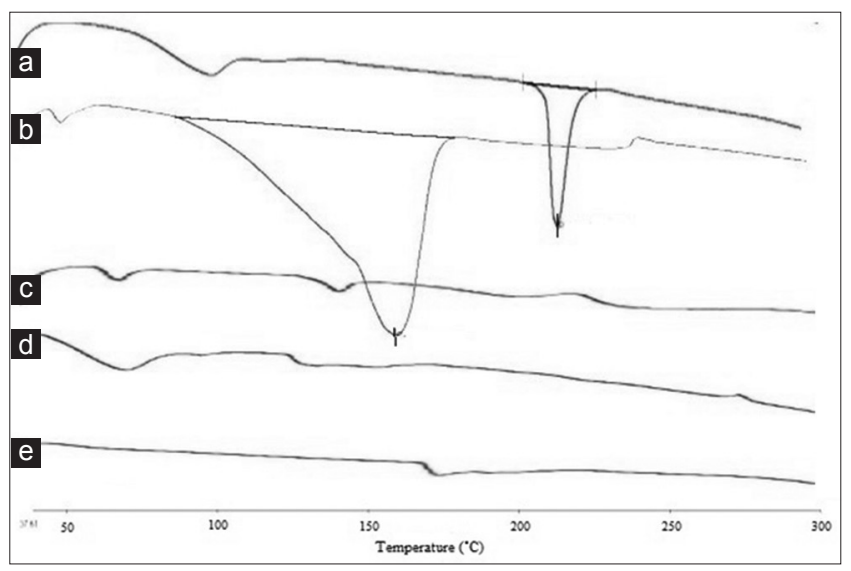

Fig. 3: Thermogram: (a) Tetrandrine, (b) $\mathrm{CaCl}_{2}$, (c) pectin, (d) capectinate beads without tetrandrine, (e) ca-pectinate beads with tetrandrine

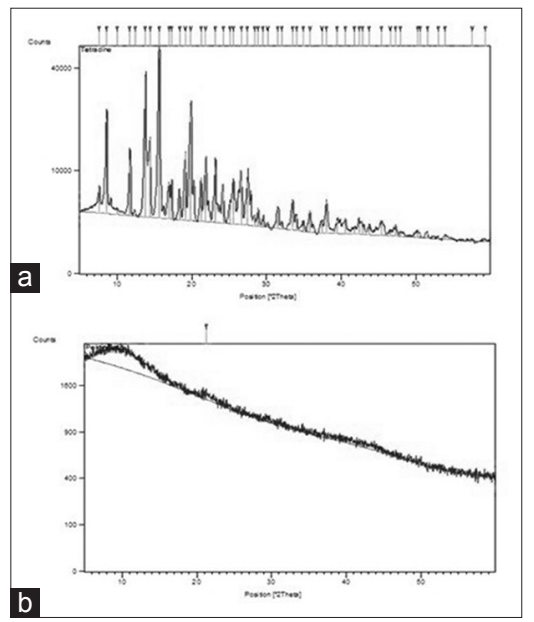

Fig. 4: X-ray diffraction patterns, (a) tentrandrine, (b) capectinate beads containing tetrandrine

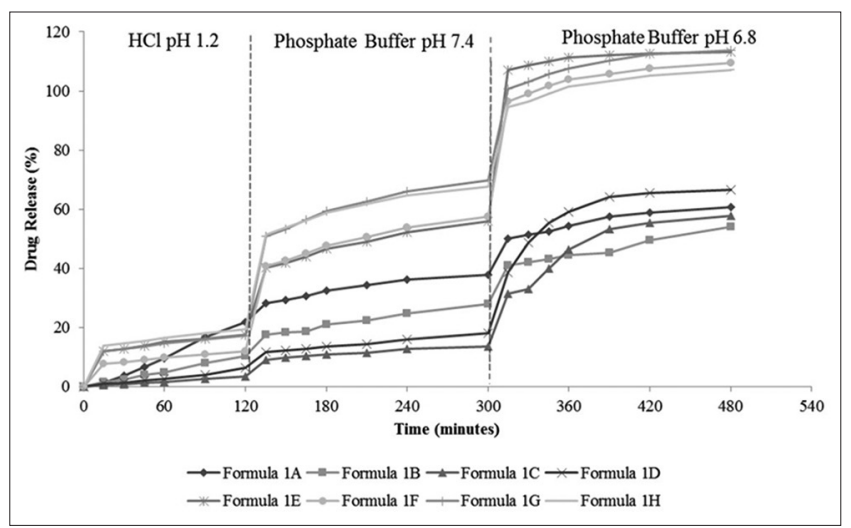

Fig. 5: Cumulative drug release profile of Formula $1 \mathrm{~A}-1 \mathrm{H}$, Data are expressed as mean \pm SD $(n=3)$. Formula 1A: 10\% Eudragit L10055 coat; Formula 1B: 12.5\% Eudragit L100-55 coat; Formula 1C: 10\% Eudragit L100 coat; Formula 1D: 12.5\% Eudragit L100 coat Formula 1E: 10\% HPMCP HP-55 coat; Formula 1F: 12\% HPMCP HP-55 coat; Formula 1G: 10\% CAP coat; Formula 1H: 15\% CAP coat
Eudragit L100-55, which were $13.58 \%$ and 18.29 for Formula 1C and $1 \mathrm{D}$, respectively.

In phosphate buffer $\mathrm{pH}$ 6.8, it was expected that the drugs would completely release. The drug release in minute 315 was increased significantly. This was caused by the coating layer which had been eroded and in phosphate buffer 6.8, beads could well expand thus it helped the drug release. The cumulative drug release result in Formula $1 \mathrm{~A}$ was $60.74 \%, 1 \mathrm{~B}$ was $54.04 \%, 1 \mathrm{C}$ was $57.87 \%$, and $1 \mathrm{D}$ was $66.54 \%$.

After $8 \mathrm{~h}$, all beads coating with phthalate polymer reaching 100\% release in the colonic simulated medium, $1 \mathrm{E}$ was $113.13 \%$, and $1 \mathrm{~F}$ was $109.34 \%$ while $1 \mathrm{G}$ was $113.64 \%$ and $1 \mathrm{H}$ was $106.95 \%$. From the test, it can be concluded that beads coating with methacrylate polymer is sufficient to resist tetrandrine released than phthalate polymer.

Based on in-vitro results, beads with 10\% Eudragit L100 coat had the lowest drug release cumulative in $\mathrm{HCl} \mathrm{pH} 1.2$ and phosphate buffer $\mathrm{pH}$ 7.4. Then, when entering phosphate buffer medium $\mathrm{pH} 6.8$, the drug release was significantly increased. Therefore, Formula $1 \mathrm{C}$ was chosen to be used in in-vivo targeted test. These results are demonstrated in Fig. 5.

In-vitro drug release was tested in hydrochloride acid $\mathrm{pH} 1.2$ medium as a gastric acid fluid simulation for $2 \mathrm{hr}$, phosphate buffer $\mathrm{pH} 7.4$ as small intestine fluid simulation for $3 \mathrm{hrs}$, and phosphate buffer $\mathrm{pH} 6.8$ as colon fluid simulation for $3 \mathrm{hrs}$. This release test carried out without the presence of enzymes, while in fact, enzymes would trigger more drug release mechanism.

\section{In-vivo targeted test}

Beads formula with Eudragit L100 10\% coat was chosen as a formulation with the best in-vitro profile which then used in in-vivo drug targeted test using rats. Before the intervention, the rats were fasting for 1 day to clean the gastrointestinal tract from food or feces thus facilitate the observation. According to the time orientation, we chose $2.5 \mathrm{hr}$ as the most suitable dissection time for observation. $2 \frac{1}{2} \mathrm{hrs}$ after beads injection, rats were dissected and observed to define the colon condition. These results were demonstrated in Table 3.

According to the result of control rats, we found no beads in rats gastrointestinal tract, beads without a coat was expected had been degraded by gastric $\mathrm{pH}$ before reached the intestine. In rat 1 , we found beads in the gastric with the coat still could be found; in rat 2, we found beads in the intestine in $64 \mathrm{~cm}$ distance from the end of gastric (antrum) with the thin coat still could be found; then in rat 3, we found beads in the intestine in $90 \mathrm{~cm}$ distance from the end of gastric (antrum), beads in this condition found expanded and we could not find any coat left. According to these results, beads reached an average distance of $77 \mathrm{~cm}$ from the end of gastric (antrum), which was still in jejunum part [16]. Beads found in rat gastrointestinal tract showed coated beads toleration against $\mathrm{pH}$ of the upper gastrointestinal tract. Furthermore, gastrointestinal tract distance from each rat also affect the study results.

\section{Table 3: Observation results of in-vivo targeted test}

\begin{tabular}{lll}
\hline Group & Animal & Observation results \\
\hline Control & Rat 1 & No beads found \\
& $\begin{array}{l}\text { Rat 2 } \\
\text { Rat 3 }\end{array}$ & \\
Calcium pectinate beads & Rat 4 & Beads found in gastric \\
coated by Eudragit & Rat 5 & $\begin{array}{l}\text { Beads found in intestine in } \\
64 \text { cm distance from the end } \\
\text { L-100 10\% }\end{array}$ \\
& Rat 6astric \\
& & $\begin{array}{l}\text { Beads found in intestine in } \\
\text { 90 cm distance from the end } \\
\text { of gastric }\end{array}$ \\
\hline
\end{tabular}




\section{CONCLUSION}

Calcium pectinate beads production containing tetrandrine was performed using ionotropic gelation method which produced beads in a spherical shape and brownish yellow color. In shape characterization, surface morphology, size, water content, entrapment efficiency tests, the results differed between the various calcium chloride concentrations used which were $5 \%, 10 \%$, and $15 \%$. The beads size, water content, and entrapment efficiency were increased following the increased calcium chloride concentration used. Formula 1 used as the best beads characterization. Formula 1 had an average size of $832.23 \mu \mathrm{m}$, water content was $28.75 \%$, and the entrapment efficiency was $65.67 \%$. Formula 1 then coated with Eudragit L100-55, Eudragit L100, HPMCP HP-55 or CAP. In addition, in-vitro release study showed that beads which were coated with Eudragit L100 could hold the drug release in the upper gastrointestinal tract better than others. Formula 1C (beads coated with 10\% Eudragit L100) was chosen as a formulation with the best in-vitro profile which showed an optimal protection from gastric acid. Moreover, the in-vivo targeted test showed that Formula $1 \mathrm{C}$ could deliver the beads to the intestine compared to the control beads.

\section{ACKNOWLEDGMENTS}

The authors gratefully thank Dr. Sutriyo and PT. Jebsen Jessen Ingredients, Indonesia for supplying Eudragit L100 and L100-55. The authors also gratefully acknowledge the financial support for this study by Faculty of Pharmacy, Universitas Indonesia Grant Research: Young Lecturer Research (No. 027/UN2.F11.D5/HKP.05.00/2016).

\section{REFERENCES}

1. Sriamornsak P. Chemistry of pectin and its pharmaceutical uses: A review. Silpakorn Univ Int J 2003;3(1-2):207-28.

2. Philip AK, Philip B. Colon targeted drug delivery systems: A review on primary and novel approaches. Oman Med J 2010;25(2):79-87.

3. Das S. Targeted Delivery of Resveratrol for Colon (Doctoral Dissertation); 2009. Available from: http://www.scholarbank.nus.edu. sg/bitstream/handle/10635/16565/Das\%20S.pdf.pdf?sequence=1.

4. Amidon S, Brown JE, Dave VS. Colon-targeted oral drug delivery systems: Design trends and approaches. AAPS PharmSciTech
2015;16(4):731-41.

5. Rowe R, Sheskey P, Quinn M. Handbook of pharmaceutical excipients. Handbook of Pharmaceutical Excipients. $6^{\text {th }}$ ed. London: APhA/ Pharmaceutical Press; 2009.

6. Luangmonkong T, Suriguga S, Bigaeva E, Oosterhuis D, de Jong KP, Schuppan D, et al. Antifibrotic Efficacy of a TGF- $\beta$ Kinase Inhibitor on Early-Onset and End-Stage of Fibrosis in Precision-Cut Human Liver Slices; AASLD LiverLearning; 2015:110678. Available from: https// www.liverlearning.aasld.org/aasld/2015/thelivermeeting/110678/ theerut.luangmonkong.antifibrotic.efficacy.of.a.tgf-.kinase.inhibitor. on.html.

7. Iswandana R, Pham BT, van Haaften WT, Luangmonkong T, Oosterhuis D, Mutsaers HA, et al. Organ- and species-specific biological activity of rosmarinic acid. Toxicol In Vitro 2016;32:261-8.

8. Westra IM, Oosterhuis D, Groothuis GM, Olinga P. Precision-cut liver slices as a model for the early onset of liver fibrosis to test anti-fibrotic drugs. Toxicol Appl Pharmacol 2014;274(2):328-38.

9. Latella G, Sferra R, Speca S, Vetuschi A, Gaudio E. Can we prevent, reduce or reverse intestinal fibrosis in IBD? Eur Rev Med Pharmacol Sci 2013;17(10):1283-304

10. Snejdrova E, Dittrich M. Pharmaceutical applications of plasticized polymers. In: Recent Advances in Plasticizers. Croatia: InTech; 2012. p. 69-90.

11. Prajapati SK, Tripathi P, Ubaidulla U, Anand V. Design and development of gliclazide mucoadhesive microcapsules: In vitro and in vivo evaluation. AAPS PharmSciTech 2008;9(1):224-30.

12. Tripathi GK, Singh S. Formulation and in vitro evaluation of $\mathrm{pH}-$ sensitive oil-entrapped buoyant beads of clarithromycin. Trop J Pharm Res 2010;9(6):533-9.

13. Mohanty S, Panigrahi AK. Multiparticulate drug delivery system for colon targeting. Int J Pharm Pharm Sci 2015;7(3):433-6.

14. El-Menshawe SF, Abdeltwab AM, Mohamed AI. Novel gastro-retentive polymeric microspheres: An approach for increased bioavailability and an once daily dosing of terbutaline sulfate. Int J Pharm Pharm Sci 2016;8(8):320-9

15. McCarry P. Investigation into the Production of Calcium Pectinate Particles for Oral Delivery to the Colon (Master Dissertation); 2011. Available from: http://www.etheses.bham.ac.uk/2879/1/McCarry_11_ Mres.pdf.

16. Vdoviaková K, Petrovová E, Maloveská M, Krešáková L, Teleky J, Elias MZ, et al. Surgical anatomy of the gastrointestinal tract and its vasculature in the laboratory rat. Gastroenterol Res Pract 2016. 